\title{
AC 2012-4986: BROADENING PARTICIPATION ACTIVITIES AT UPRM THROUGH THE NATIONAL SCIENCE FOUNDATION BRIGE PROGRAM
}

\section{Dr. Aidsa I. Santiago-Romn, University of Puerto Rico, Mayagez}

Aidsa I. Santiago-Romn is an Assistant Professor in the Department of Engineering Science and Materials and the Director of the Strategic Engineering Education Development (SEED) Office at the University of Puerto Rico, Mayagez (UPRM). Santiago earned a B.A. (1996) and a M.S. (2000) in industrial engineering from UPRM, and a Ph.D. (2009) in engineering education from Purdue University. Her primary research interest is investigating students' understanding of difficult concepts in engineering science with underrepresented populations. She also teaches introductory engineering courses such as problem solving and computer programming, statics, and mechanics.

\section{Dr. Pedro O. Quintero, University of Puerto Rico, Mayagez}

Pedro Quintero earned a B.S. in mechanical engineering from the University of Puerto Rico, Mayagez and an M.S .from that same institution. After spending nine years in the electronics industry, he joined the University of Maryland, College Park, where he earned a Ph.D. degree in mechanical engineering. He joined the Department of Mechanical Engineering of the University of Puerto Rico, Mayagez, in 2008 as an Assistant Professor.

\section{Dr. Guillermo J. Serrano, University of Puerto Rico, Mayagez}

Guillermo Serrano received the B.S. degree in electrical engineering from the University of Puerto Rico, Mayaguez, Puerto Rico, and the M.S. and Ph.D. degrees in electrical engineering from the Georgia Institute of Technology, Atlanta, in 2003 and 2007, respectively. He is currently an Assistant Professor in the Electrical and Computer Engineering Department at the University of Puerto Rico. His current research interests include data converters, voltage/current references, oating-gate MOS transistors, and micro-energy harvesting circuits systems. 


\section{Broadening Participation Activities at UPRM through the National Science Foundation BRIGE Program}

\section{Introduction}

The Broadening Participation Research Initiation Grants in Engineering (BRIGE) program at the National Science Foundation (NSF) is part of the Directorate for Engineering (ENG) and offers funding opportunities to all beginning engineers with the intent of increasing the diversity of researchers in the engineering disciplines. The goal of the program is to increase the number of proposals from individuals who can serve as role models and mentors for an increasingly diverse engineering student population. BRIGE aims to support innovative research and diversity plans that contribute to recruiting and retaining a broad range of engineering researchers, especially those from groups that are underrepresented in the engineering population. The College of Engineering at the University of Puerto Rico, Mayaguez Campus (UPRM) has an enrollment of about 5000 students (approximately 98\% are Hispanic), 67\% males and 33\% females. Because of this, UPRM researchers have an excellent opportunity to impact both Hispanics and women, who are traditionally underrepresented populations in engineering.

Currently, there are three active research endeavors funded through the BRIGE program at UPRM. The objective of this paper is to disseminate the broadening participation initiatives that have been designed and implemented at UPRM through these projects. The first project seeks to provide research experience to senior undergraduate and graduate Hispanic students in the design, fabrication, and testing of microelectronic devices. Specifically, this grant has sponsored the research efforts of 3 graduate and 5 undergraduate students, but also outreach efforts have impacted around 70 high school students from the public education system. Additionally, 7 senior undergraduate students have been indirectly impacted through a special topic course, from which 2 of the participating students were able to publish and participate in a peer-review conference. The overall objective of the second project is to initiate a research program to broaden participation and increase opportunities of Hispanic engineering students so that they can become engaged in research as independent investigators. With this project, two courses have been developed for undergraduate research that has impacted about 80 students. Four of these students went to work as mentors to 48 high school girls and boys at a Mechanical Engineering Summer Camp. During the 6-day camp, students were introduced to ME as a career and were also exposed to laboratory activities in diverse areas. Finally, the goals of the third project are to develop a Spanish version of the statics concept inventory (CATS) and to determine if bilingual students exhibit the same misconceptions as those identified in CATS. This study has broadened the participation of underrepresented groups in two ways: 100\% of the participants are Hispanic students, something that hasn't occurred previously in a study of this type; and graduate and undergraduate students working on the project are female and Hispanic. 


\section{About UPRM}

The University of Puerto Rico (UPR) is a system of eleven units distributed around the island. The main campuses are the Río Piedras Campus, the Medical Sciences, and the Mayagüez Campus. More than $90 \%$ of our student population is of Hispanic origin. ${ }^{2}$ The engineering programs at the University of Puerto Rico in Mayagüez were initiated in 1913, two years after the campus was founded as a Land Grant Institution in 1911. The broad based undergraduate programs have been highly successful. Today, we have broad ABET-accredited undergraduate programs as well as strong graduate programs in Civil, Chemical, Computer, Electrical, Industrial and Mechanical Engineering. Moreover, UPRM has played a critical role in the training of future Hispanic scientists and engineers in Puerto Rico and the United States. The College of Engineering $(\mathrm{CoE})$ is among the largest engineering institutions in the United States, ranking fifteen in the nation in undergraduate enrollment. The CoE of UPRM admits the top students from high schools in Puerto Rico. Some key national rankings as described by the ASEE Profiles of Engineering and Engineering Technology Colleges published in June 2010 include:

- Number 1 in Engineering Bachelor's degrees awarded to Hispanics (614);

- Number 3 in Percentage of Bachelor's degrees awarded to women (39.6\%);

- Number 3 in Engineering Bachelor's degrees awarded to women (243);

- Number 15 in Engineering Undergraduate Enrollment (4,981);

- Number 26 in Engineering Bachelor's degrees awarded (614).

During the last five years, the UPRM had an average of five thousand engineering students, admitting every year an average of seven hundred and sixty (760) freshmen students. In terms of admissions to UPRM's College of Engineering, a reduction trend has been observed for the last two years as shown in Figure 1. Studies are being conducted in campus regarding these issues and several factors are being considered, including the decline in the population in Puerto Rico as provided by the 2010 census data ${ }^{3,4}$ However, it is clear that we need to

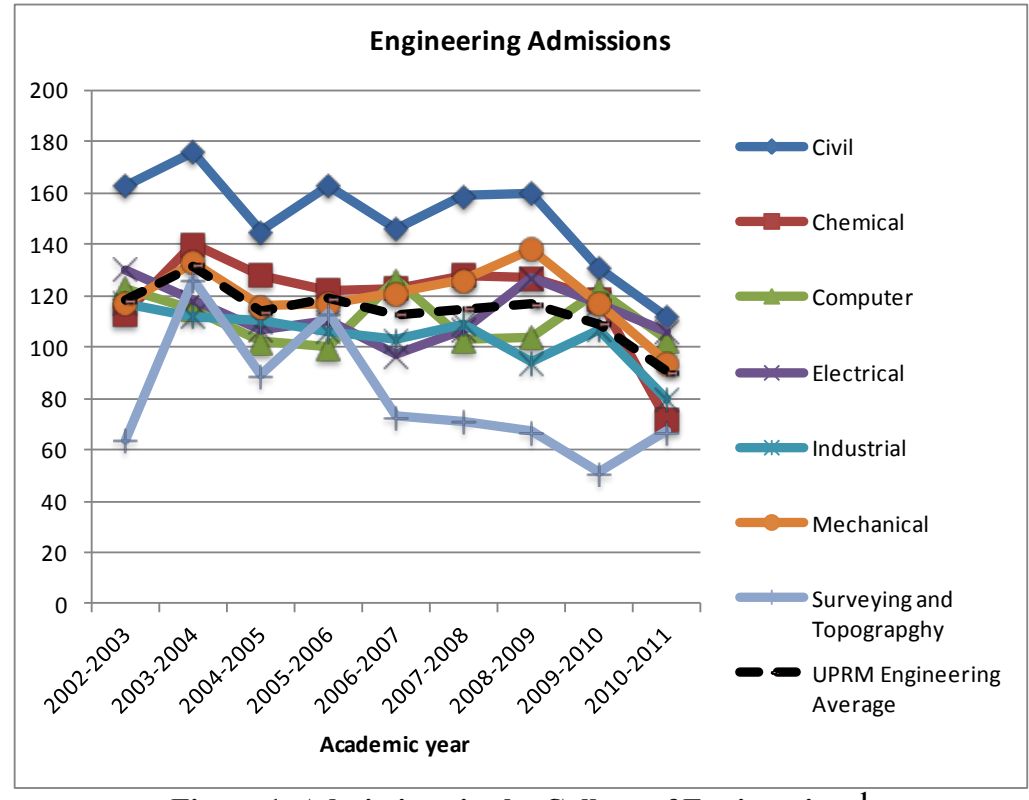

Figure 1. Admissions in the College of Engineering. ${ }^{1}$ improve the situation and motivate more qualified students to enroll in our programs to strengthen studies in the STEM areas. 
In 2009 the PI of this grant was awarded a BRIGE grant from the US National Science Foundation (NSF) aimed at providing research experience for Hispanic engineering students in the design, fabrication, and testing of microelectronic devices. These experiences seek to complement their academic preparation, allowing for the training of the next generation of Hispanic professionals in the area of integrated circuit design. Additionally, this work also contributed to the educational infrastructure required to attract and train future minority engineers through the development of outreach activities for high school student of the public education system of Puerto Rico.

This work has directly impacted 3 graduate students and 5 undergraduate. Through this work the students have actively participated in the design, fabrication and validation process of a microelectronic circuit. This award has allowed these students to fabricate and test their own circuit designs, an experience which is not typical at the undergraduate level. Graduate and senior students have serve as mentors by providing younger students with guidance and facilitating their incorporation to the research activities. The students were provided with the opportunity of publishing their experimental results in IEEE peer-reviewed conferences; 2 students were able to actively participate in international conference. Additionally collaboration with a fellow professor at UPRM, has been established.

Outreach efforts sponsored through this grant have impacted around 70 high school students from the public education system. The PI, along with his undergraduate students, created a series of hands-on experience that incorporated some basic concepts of the proposed work such as conductivity and energy harvesting. Specifically, in a one day outreach activity the students were able to participate in the construction of a home-made solar oven and the assembly of a simple circuit (refer to Figure 2). The undergraduate students actively participated as team leaders allowing them to develop their communication and leadership skills. Also, a 1 day outdoors activity was also celebrated in the Martin Garcia School, at Toa Baja, were several demonstration were performed by undergraduate students. It should be noted that although the PI was the head of the technical part of the after mentioned activities, the organizational aspect was conducted by Institutes with ongoing outreach efforts at UPRM. The activities carried out with this grant were conducted in collaboration with the University Institute for the Community Development and the Technology for the Community Center. 
In 2008, NSF awarded this BRIGE grant which aimed at initiating a research program to broaden the participation and increase the opportunities of Hispanic engineering students at the University of Puerto Rico so that they could become engaged in research as independent investigators. The outreach and broadening participation plan was tailored to impact three main areas: i) Undergraduate research activities, ii) Graduate research projects and mentoring experiences, and iii) Support to the ME Summer Camp.

The Mechanical Engineering curriculum consists of one hundred and sixty (160) credit-hours that are taken over a five year period. The curriculum aims to foster innovation and creativity through these five years, starting from the freshman year with the Creative Design 1 and 2 courses (INME 3809 and INME 3810). These courses were developed as part of the NSF Award \#DMI-9413880 project titled Manufacturing Engineering Education Partnership (MEEP) more than ten years ago when UPRM participated as one of the developers, along with Penn State, the University of Washington and the Sandia National Labs. ${ }^{5}$

At the undergraduate level, two courses within the Department of Mechanical Engineering at UPRM have been developed. The first course is INME 4998 which has been offered during the Fall 2010 and Spring 2011 semesters. It is an undergraduate research course in which students meet on a weekly basis with the PI and his graduate students, during these meetings students are asked to present an oral talk of 20 minutes in a specific topic of nanotechnology. This talk is followed by a question and answers session and open discussion. Every week two students are scheduled to present, so far a total of $\sim 30$ undergraduate students have been impacted. From this group of students, a selected group is been incorporated into the daily research activities in our laboratory and they go to work as assistants to graduate students. The second course that has been developed is INME 5015 "Mechanical Fundamentals of Electronic Packaging", which was initially offered during the Fall 2009 and offered again in the Fall 2011. A total of $\sim 50$ undergraduate students have been impacted by this effort. The course focuses on the mechanical fundamentals of electronic packaging and exposes the students to up-todate information that can lead insights to our research group activities. For the mentoring aspects of this effort, a tiered structure has been developed

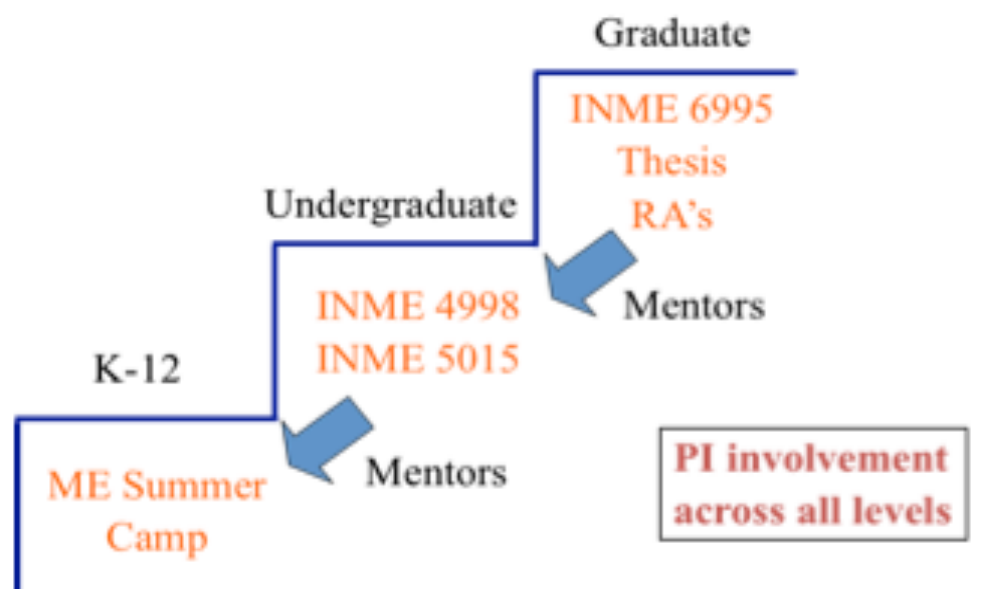

Figure 3. Tiered structure developed within Quintero's group. within our group where mentoring goes across all levels as shown in Figure 3.

The ME Department Summer Camp initiated in 2004, financed through donations from industry and the Department of Education, aimed at sophomore and junior high school students. The camp provides activities related to ME to create awareness about what Mechanical Engineers 
really do. The original motivation of this summer camp was to increase the number of female students in Mechanical Engineering, therefore between the years 2004-2009 the camp was offered only to female students. In 2011 aditional funding was obtained through the NSF BRIGE grant which enabled us to offer this camp to male students. Two sessions of twenty-two students each, one for female and another for male students were offered during this period. After this experience we understand that it is important and necessary to continue the summer camp for both gender groups, since the need to motivate and provide a better understanding of the mechanical engineering profession exists for all of them. Funding from the BRIGE grant was used for procuring the $\mathrm{LEGO}^{\circledR}$ Mindstorms ${ }^{\circledR}$ Robots; it also provided funds for laboratory demonstrations and materials. As human resources, the PI was involved in daily talks, laboratory demonstrations, and conferences. PI's graduate students served not only as mentors for the camp but also helped develop the activities as depicted in Figure 4.
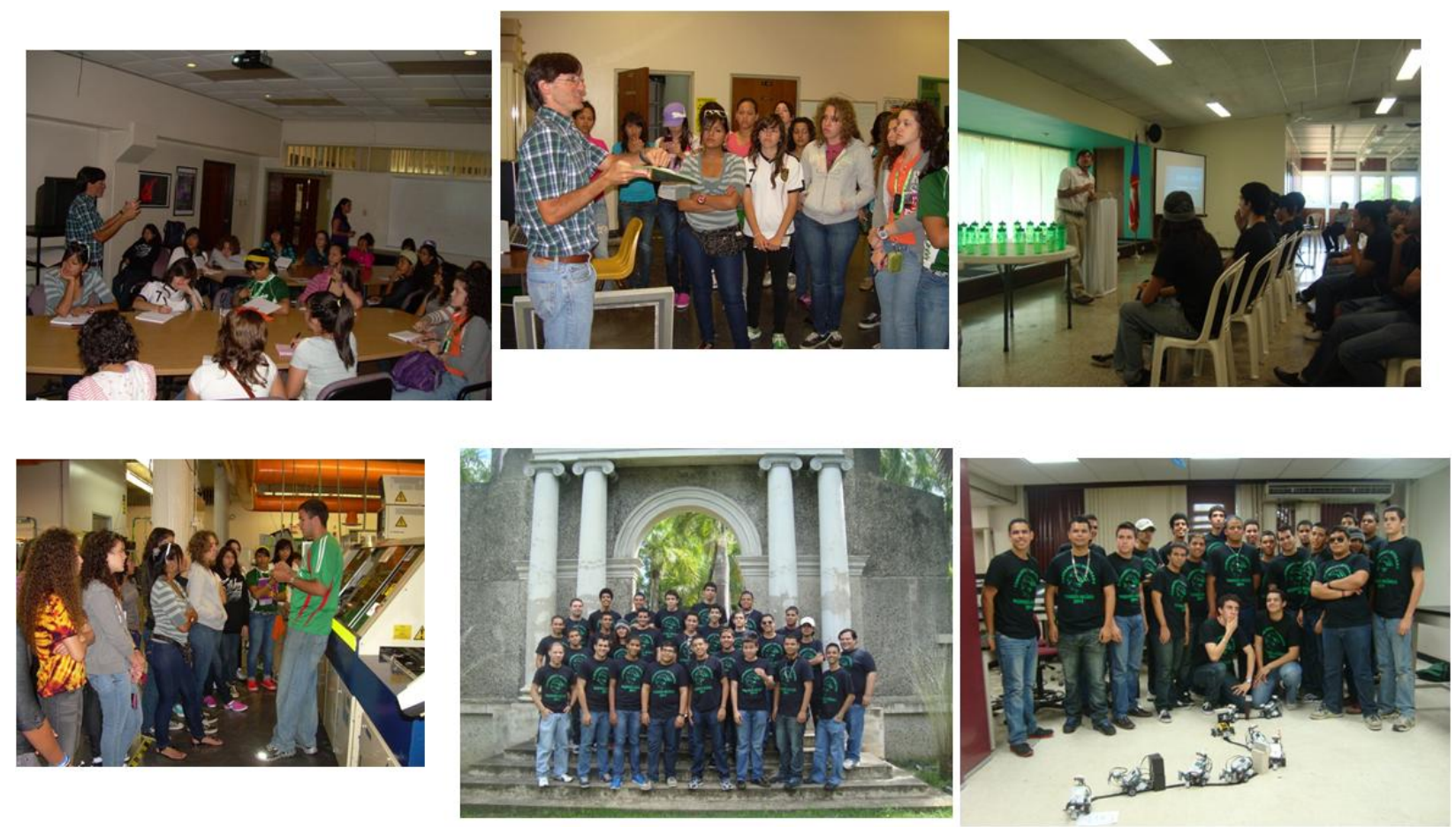

Figure 4. ME Summer Camp 2011.

\section{Project \#3 - PI Dr. Santiago; EEC - 1032563}

Finally, in January of 2010, the NSF awarded a BRIGE grant aimed at testing the efficacy of the statics concept inventory (CATS) among bilingual Hispanic students at UPRM. Since engineering students at UPRM are bilingual - they read, talk, and write both in English and Spanish - a group of professors at UPRM used the CATS as a pre/post test in their statics courses. In general, students' post-test average scores executed very low (around 29\%) in comparison to results from other institutions. Very little work has been done on language and cultural difficulties that students might encounter while using CIs. Findings from this study will expand the literature of concept inventories. The methodology established in this study will be applied with other engineering CIs with the goal to implement them on various engineering 
courses at UPRM. The goal is to assess students' understanding of specific domain concepts; and therefore providing students with a better learning experience.

The broadening participation activities within this study are aimed to broaden the participation and increase the opportunities of Hispanic engineering students at the University of Puerto Rico so that they could become engaged in research in engineering education, an area of research that was unexplored at UPRM. The research and broadening participation plan had two main objectives: 1) test the efficacy of the statics concept inventory (CATS) at UPRM with bilingual students, and 2) create awareness of Engineering Education Research.

Objective 1: Efficacy of CATS at UPRM. The research plan designed for this study consisted of different activities in which both Hispanic faculty and students were recruited to participate. The first activity consisted of translating the CATS questions into Spanish. During the spring semester of 2011, four (4) Hispanic experienced engineering professors translated all 27 CATS questions. They were asked to pay attention to the wording used, not to change the intended objective. We had at least two translations per questions that were compared, which resulted in CATS-S v1. For the second activity, ten (10) graduate students from civil engineering participated in a pilot study. They were asked to answer all 27 items of CATS-s v1, rate the clarity of each question, and provide suggestion to improve unclear questions. Nine (9) of the students completed their BA at a Hispanic University from Latin America. CATS-s v2 was then created after analyzing their responses. Finally, the third activity completed so far consisted of testing the protocol to identify if bilingual students exhibit the same misconceptions (common errors) than those currently identified in CATS. Ten (10) Hispanic senior students from the civil engineering department were recruited. They were divided into two groups, control and experimental. The control group was assigned the original CATS (English version), while the experimental group received the CATS-S v2. For both instruments the alternatives were eliminated, i.e. questions were given in open-ended format. Then, each student was given a weekend to work with the assigned instrument, independently. Interviews were scheduled for each one of them, for which a research assistant asked them to explain their thought process, i.e. what they did to solve the problem and why. These interviews were tape-recorded, transcribed, and are currently being analyzed. Research protocols for these activities were al approved by the Institutional Review Board (IRB). Preliminary analysis validates findings from previous work ${ }^{6}$, 7,8 that indicated the presence of misconceptions from basic engineering concepts among senior engineering students. Summarizing, the research activities completed so far has involved 4 Hispanic professors and 20 Hispanic engineering students. Remaining research activities are expected to involve 50 more students.

Objective 2: Awareness of Engineering Education Research. Engineering education is a field that hasn't been exploited to its potential at UPRM. Streveler et al. ${ }^{9}$ have identified various levels of inquiry within engineering education research (refer to Figure 5). The levels in the figure fluctuate from 0 to 4 . Level 0 , located at the bottom of the triangle, represents those who do not view engineering education research as "research" but as a "way of teaching". On the contrary, Level 4, located at the top portion of the figure, represents those who view and are considered engineering education researcher mainly because they conduct rigorous research and publishing scholarly work in this field. At UPRM a handful of researchers can be allocated in Level 4, thus the goal is to increase the number of proposals and research activities at this level. 


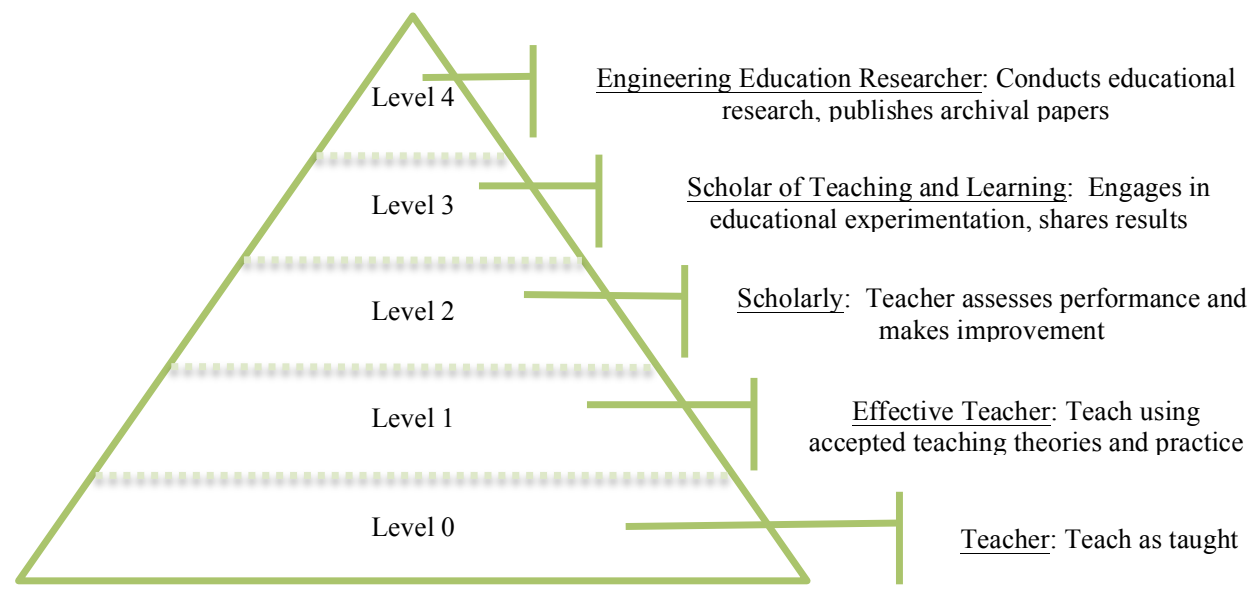

Figure 5 - Levels of Inquiry in Engineering Education Research

One of the primary goals of the Dean of Engineering is to promote and increase engineering education research at UPRM, therefore the PI has been supported by the administration to promote activities that are aligned with his strategic plan. Specific activities that has resulted from this research project has been the creation of two courses: (1) Introduction to Engineering Education Research and (2) Research Methods in Engineering Education. During this academic year, a total of 7 undergraduate and 2 graduate engineering students have been enrolled in these courses. All research assistants involved in this study were required to enroll in these courses as part of their training. In total, 1 graduate student and 4 undergraduate students (all females) have been receiving assistantship from this study to participate as research assistants. Through the courses they have been reading about engineering education as a field of research. Research activities have allowed them to practice what has been learned in the courses. Similarly, seminars have been designed and offered to educate the academic community about engineering education research. Webinars from NSF program solicitations have been coordinated which has resulted in the involvement of faculty from different schools in the preparation of research proposals. During the past year, over 10 proposals related to engineering education were submitted, from which 3 have been successfully funded and over 20 papers have been published and/or presented at conference proceedings or peer reviewed journals. Several others are currently under review.

\section{Conclusions}

In summary, this program has resulted in an increase and diversification of research activities at UPRM that have been beneficial to both undergraduate and graduate students from different engineering departments. Also male and female Hispanic high school students have been engaged in research activities that have allowed them to consider engineering as a career and also to be interested in engineering research.

\section{Acknowledgments}

The authors of this paper would like to acknowledge the National Science Foundation and the University of Puerto Rico at Mayaguez for their support to the research projects addressed in tis paper. 


\section{References}

1. Quintero, P., G. Serrano, and A.I. Santiago-Román, Data provided by UPRM's Office of Institutional Research (OIIP), December, 2011: Mayaguez, PR.

2. NCES, UPRM enrollment data from http://nces.ed.gov/collegenavigator/?s=all\&zc=00680\&zd=100\&of=3\&l=5\&ct=1\&id=243197 - enrolmt, 2011.

3. Bureau, U.C., US Census Profile of General Population and Housing Characteristics: 2000, 2003, Demographic Profile Data Data downloaded through the factfinder page:

http://factfinder.census.gov/servlet/QTTable? bm=y\&geo id=04000US72\&qr name=DEC 2000 SF1 U DP1\&-ds name=DEC 2000 SF1 U.

4. Bureau, U.C., US Census Profile of General Population and Housing Characteristics: 2010, 2011, Demographic Profile Data Data downloaded through the factfinder page using topic Puerto Rico: http://factfinder2.census.gov/faces/nav/jsf/pages/index.xhtml

5. Lamancusa, J.S., J.E. Jorgensen, and J.L. Fridley. Product Dissection - A Tool for Benchmarking in the Process of Teaching Design. in Proceedings of the Frontiers in Education Conference. 1996.

6. Santiago Román, A.I., et al., Senior Engineering Students' Conceptualization of Force: The Relationship Between Two Different Conceptual Frameworks, in Paper presented at the American Educational Research Association Annual Meeting2009: San Diego, CA.

7. Clarke Douglas, T., R.A. Streveler, and A.I. Santiago Roman, Surely students know this!: Patterns of error in senior engineering students problem-solving in Statics, in Paper presented at the ASEE IL/IN Section Conference 2009: Valparaiso, IN.

8. Clarke Douglas, T., A.I. Santiago-Román, and R.A. Streveler. Does Conceptual Understanding Matter: Patterns Of Error In Senior Engineering Students Problem Solving In Statics? in 2010 ASEE Annual Conference \& Exposition. 2010. Louisville, KY.

9. Streveler, R.A., M. Borrego, and K.A. Smith, Moving from the "Scholarship of Teaching and Learning" to "Educational Research:" An Example from Engineering. . Improve the Academy, 2007. 25: p. 139-149. 